\title{
AUTOBIOGRAFÍA: EL REHÉN SINGULAR Y LA OREJA INVISIBLE ${ }^{1}$
}

\author{
Ángel G. LOUREIRO \\ University of Princeton
}

Al tener que enfrentarse con serias objecciones acerca de la capacidad de la autobiografía para representar el pasado de una vida, la crítica del género efectúa a menudo, ya desde el artículo pionero de Gusdorf (1955), un desplazamiento de un modelo epistemológico (la autobiografía como reproducción de una vida) a un modelo performativo (la autobiografía como acto de autocreación en el momento de la escritura). Estos intentos de salvaguardar la capacidad cognoscitiva de la autobiografía no responden satisfactoriamente a los reparos presentados por un Paul de Man (1991), quien no sólo cuestiona la autobiografía como mimesis sino que también muestra la presencia, en textos como las Confesiones de Rousseau, de una retórica performativa que entra en conflicto, y desestabiliza, la retórica epistemológica que se supone imperante en el género. En mi opinión, tanto las dificultades que encuentra la crítica a la hora de considerar la autobiografía como un género primordialmente cognoscitivo, como las objeciones que presenta de Man a tal modelo, son superadas si consideramos la autobiografía no como reproducción de una vida sino como un acto que es a la vez discursivo, intertextual, retórico y, fundamentalmente, ético. Para poder ir más allá de una complaciente, pero limitada, concepción de la autobiografía como referencialidad, los estudios autobiográficos deberían complementar su obsesión con lo epistemológico-cognoscitivo con una atención a lo ético. Para poder salvar las dificultades presenta-

Este artículo condensa las ideas desarrolladas en el primer capítulo de mi libro The Ethics of Autobiography. Replacing the Subject in Modern Spain, Nashville, Vanderbilt University Press, 2000. 
das por una concepción de la autobiografía considerada como una reproducción (o recreación) del yo y su pasado, propongo que se atienda a una ética de la autoescritura, considerada ésta última como un acto que responde y se dirige al otro.

\section{EL SUJETO ENDEUDADO}

Mi concepción ética de la autobiografía se apoya fundamentalmente en las teorías de Levinas, para quien la ética es prima philosophia y, como tal, opuesta y anterior a la ontología y a la epistemología. En oposición a las formulaciones ontológicas del yo, para Levinas la constitución del yo comienza en su relación con el otro, en una «intriga ética anterior al conocimiento» (Levinas 1993, pág. $158)^{2}$. El otro constituye una exterioridad y anterioridad absolutas con respecto al yo y, por consiguiente, esta relación no admite ni representación ni aprensión por medio de ningún conocimiento, puesto que «en última instancia, en el conocimiento se da siempre una imposibilidad de escapar al yo» (Levinas 1985, pág. 60). Puesto que el otro no-fenomenológico no puede ser aprehendido como un objeto, se sigue que yo no puedo hablar del otro como si fuera un tema o un objeto, sino que, por el contrario, y como escribe Derrida, «yo debo sólo hablarle al otro,» razón por la que hay que considerar que el lenguaje se da primordialmente en forma vocativa y no en forma atributiva (Derrida 1978, pág. 103).

El yo comienza como una conminación a hablar por parte de un otro que exige una respuesta, y no como un cogito o autoconciencia que se funda a sí misma: el yo se constituye como respuesta al otro y como responsabilidad hacia ese otro. Ese estadio que antecede a la construcción social del sujeto, y también a todo autoconocimiento, es el dominio de la ética tal como la entiende Levinas, quien la distingue tajantemente de lo que entendemos comúnmente por moralidad (la cual tiene como dominio las relaciones entre ciudadanos). La responsabilidad inexcusable hacia el otro se manifiesta en lo que Levinas llama «un decir [Dire] anterior a cualquier cosa que se diga [Dit]» (Levinas 1990, pág. 75), un decir que antecede e instituye la posibilidad de todo intercambio lingüístico, de toda conversación y de toda temática. Por consiguiente, la identidad le viene al yo de afuera, y en toda autoconciencia no tenemos autopresencia sino una disyunción de una identidad que está más allá de los poderes recuperativos de la memoria. Levinas identifica el «decir» con el «poder de decir,» cuya significación, olvidada en la ontología, la precede en realidad. Mientras lo «dicho» es «un acto que comienza en un ego conquistador y voluntario,» en el «decir» el sujeto

${ }^{2}$ Traduzco al castellano todas las citas para facilitar la lectura. 
renuncia a su soberanía (Levinas 1990, págs. 239 y 81) y se expone ante el otro antes de que se diga nada y antes de toda experiencia (Levinas 1989, pág. 183). El «decir es comunicación..., pero entendida como condición de toda comunicación, como apertura vulnerable [«exposition»] al otro» (Levinas 1990, pág. 82). La comunicación no es así reducible al fenómeno de la verdad. Sin embargo, el decir siempre dejará una traza en la tematización de lo dicho, haciendo dudar a éste último entre un orden de entidades y verdad, y otro orden de alteridad, diferencia, deuda y responsabilidad. En otras palabras, la verdad (autobiográfica) estará siempre atravesada por la deuda y por la culpa.

Levinas advierte repetidamente que no se asuma que la responsabilidad hacia el otro se origina en una hermandad biológica, en una libertad que preexiste al sujeto, o en un contrato inaugural con el otro. Por el contrario, la responsabilidad hacia el otro antecede a todo acuerdo legal o moral y obliga la sujeto más allá de esos acuerdos. Por otra parte, Levinas se cuida de mostrar que esa responsabilidad que constituye al sujeto como un «rehén irremplazable» del otro (Levinas 1990, pág. 240) se manifiesta diariamente «en el acontecimiento empírico de la obligación hacia el otro, como la imposibilidad de mantenernos indiferentes... ante las desgracias y las caídas del vecino» (Levinas 1989, pág. 153).

Resulta necesario mostrar las diferencias entre el tipo de alteridad propuesta por Levinas y otras teorías del otro y de la relacionalidad. El otro (ético) de Levinas no tiene nada que ver con el Otro (político) postulado con frecuencia para el choque entre sujetos de culturas diferentes, y cuyo ejemplo más aducido es el encuentro que se da en situaciones de dominio político colonial. Este Otro político en realidad es sinónimo de «diferencia», no de alteridad radical como la que, desde la perspectiva de un Levinas, subyace a todo sentido de identidad. El otro de Levinas es anterior a toda construcción política del sujeto y a toda formulación del sujeto como (auto)conocimiento.

Por otra parte, la relación entre el sujeto y el otro de Levinas es también diferente a las teorías relacionales de la identidad de la mujer propuesta por Susan Stanford Friedman, quien sigue el modelo histórico de la construcción de la identidad femenina teorizado por Sheila Rowbotham y el modelo psicoanalítico de individuación femenina postulado por Nancy Chodorow. Contrastando el modelo individualista que sigue el sujeto masculino con «el sentido relacional de la identidad femenina», Friedman aduce que ésta relacionalidad femenina se debería a la especial conexión que las hijas mantienen con sus madres, influencia ininterrumpida que se mantiene aún más allá de la fase edípica. Ese sentido relacional de la identidad femenina haría que la mujer viera su identidad no como aislada o individual sino como una solidaridad con los otros (Friedman 1994, pág. 
166). Partiendo de estas ideas acerca de las diferencias en la construcción social del hombre y la mujer, Friedman postula que no se puede aplicar a las mujeres (y a las minorías) un modelo individualista que considera al sujeto como un ente autónomo, pues hay marcadas diferencias en la construcción social entre hombres y mujeres (Friedman 1994, pág. 152). La diferencia esencial entre esta relacionalidad, exclusivamente femenina y minoritaria, y la alteridad postulada por Levinas reside de nuevo en que la última, además de ser universal (conformado igualmente al hombre y a la mujer), se da en un plano, el ético, que es no sólo anterior a toda construcción social como la postulada por Friedman, sino que además sirve de base afectiva para esas construcciones.

Otro tipo de relacionalidad con el otro es la propuesta por Doris Sommer (1994) en su estudio de los testimonios de mujeres latinoamericanas, en los que desvela una interpelación de la hablante a sus oyentes y lectores(as) en busca de su complicidad política, aunque esos destinatarios interpelados son mantenidos a una distancia infranqueable de la hablante debido a la imposibilidad de una identificación total entre ésta y aquéllos(as). Esta relación entre sujeto y otro es una relación de alteridad política y comunicativa y difiere obviamente de la alteridad ética de Levinas. Sin embargo, como aduciré más adelante, la insoslayable relación de deuda entre el yo y el otro se manifiesta en la autobiografía no sólo en los modos de la construcción de la identidad, sino también en los términos que los(as) autobiógrafos(as) usan para dirigirse a un(a) destinatario(a) privilegiado(a) que encarnaría así la responsabilidad hacia el otro fundamental para todo sujeto. Toda autobiografía, y no sólo los testimonios de mujeres, se dirige a un otro en una relacionalidad insoslayable que sin embargo marca también una distancia insalvable entre el sujeto y un destinatario que no coincide simplemente con los(as) lectores(as). Intentaré mostrar, además, que esa relacionalidad comunicativa de toda autobiografía se manifiesta a través de la figura retórica del apóstrofe.

Las formulaciones de Levinas no bastan en sí mismas para un análisis de la autobiografía, pues atienden fundamentalmente a la originación ética del sujeto, pero apenas abordan las dimensiones políticas del mismo. En este sentido Derrida aduce que el lenguaje de Levinas incurre en un lenguaje de no violencia y de pura adoración del otro, el cual arranca al sujeto de la historia (Derrida 1978, pág. 147). De todos modos, el mismo Levinas es consciente de que la ética no es suficiente, pues «dado que hay más de dos personas en el mundo, invariablemente pasamos de la perspectiva ética de la alteridad a la perspectiva ontológica de la totalidad... En el momento en que hay tres personas, la relación ética con el otro se convierte en política» (Kerney 1984, págs. 57-58). Se impone por lo tanto la necesidad de 
complementar un análisis ético (en el sentido de Levinas) prestando atención a las dimensiones político-discursivo y retóricas de toda autobiografía.

Esta necesidad no debe hacernos creer que en el terreno de la política encuentra el sujeto una voz o presencia propia, un autoconocimiento, pues como señalan Deleuze y Guattari, «no hay enunciación individual,» sino que toda enunciación es social y todo discurso es indirecto (Deleuze y Guattari 1994, pág. 79). En consecuencia, dicotomías como yo auténtico y yo alienado (o, en otro nivel, ciencia e ideología) constituyen una alternativa falsa e idealista. El sueño de encontrar o liberar un yo auténtico no es más que un efecto discursivo. Toda autobiografía está escrita en el contexto de prácticas e instituciones que posibilitan que los(as) autobiógrafos(as) hablen de sí y que conforman las estrategias autobiográficas. De ese modo, toda autobiografía recurre necesariamente a la mediación de discursos científicos, filosóficos, psicológicos, históricos, políticos, morales, religiosos, sexuales y literarios (entre otros muchos) que prevalecen en una época determinada. Está claro que ningún discurso determinado debe prevalecer en el desvelamiento de esa multiplicidad que constituye el sujeto. Por otra parte, no hay un yo alienado en el sentido idealista que supone la posibilidad de una liberación o descubrimiento de un presunto yo verdadero, pues el yo está perpetuamente alienado. Como declara Deleuze, refiriéndose a Foucault, la historia «no fija nuestra identidad, sino que la dispersa en nuestra alteridad esencial» (Deleuze 1995, pág. 95). De todos modos, aunque muchos autobiógrafos parezcan creer en la posibilidad de encontrar su yo verdadero, esa creencia no debe ser considerada una ficción. De hecho, es bastante común que un(a) autobiógrafo(a) vea su vida como un proceso de liberación de autoimágenes falsas o impuestas con coerción, o como un proceso de reencuentro con lo que él o ella considera ser su verdadera identidad. Sin embargo, nuestro escepticismo respecto a este modelo de vida como viaje o lucha en busca de la verdad personal no implica que ese modelo sea una ficción para quien escribe, dado que la verdad de la autobiografía no reside en la verdad intrínseca de lo que se narra sino en su capacidad de dar forma a una vida, de producir autoentendimiento. Y esa es la única verdad que podemos esperar de una autobiografía: la creencia, de quien escribe, en su propia verdad, pero no la verdad como adecuación a una experiencia pasada. El sujeto no puede desprenderse de los discursos que dan forma a su vida, pero no por eso es una víctima de una ideología sofocante o alienante.

\section{LAS MÁSCARAS DEL SUJETO Y LA OREJA DEL OTRO}

Podemos volver ahora a una reconsideración del desplazamiento al que me refería antes y que efectúan muchos teóricos de la autobiografía cuando dejan de 
centrarse en el pasado para concentrarse en el presente de la escritura postulando que en ese acto el sujeto más que reproducir su vida se recrea a sí mismo. En primer lugar, conviene resaltar que en el presente de la escritura el sujeto no tiene acceso a una mayor verdad acerca de sí mismo, dado que el acto de autonominación sólo puede efectuarse por medio del préstamo de discursos colectivos: como ya hemos visto siguiendo a Deleuze y Guatari, el sujeto sólo puede hablar indirectamente.

Pero además, si consideramos el presente de la escritura autobiográfica no ya temáticamente, sino como decir, nos encontramos que la autobiografia proclama la identidad como un gesto que repite esa dimensión ética postulada por Levinas según la cual el sujeto se origina como respuesta y responsabilidad hacia el otro. Por consiguiente, y como ya señalé, en este nivel del decir el lenguaje funciona como vocativo y no como predicativo. Esto nos lleva a una consideración del papel de la retórica en la autobiografía y, en particular, a la función esencial del apóstrofe. En su famoso artículo «La autobiografía como desfiguración,» Paul de Man postula que la prosopopeya, la figura que consiste en dar voz y rostro a lo ausente o inanimado, sería la figura fundamental de la autobiografía. Pero, al mismo tiempo, como señala de Man, «[e]n cuanto entendemos que la función retórica de la prosopopeya consiste en dar voz o rostro por medio del lenguaje, comprendemos también que de lo que estamos privados no es de vida, sino de la forma y del sentido de un mundo que sólo nos es accesible a través de la vía despojadora del entendimiento. La autobiografia vela una desfiguración de la mente por ella misma causada» (De Man 1991, pág. 118). En otras palabras, al tiempo que da rostro («figura»), la prosopopeya simultáneamente «desfigura.» Pero esta abolición del sueño restaurador de la autobiografía sólo puede mantenerse si insistimos en considerar la autobiografía como una operación cognoscitiva. $\mathrm{Si}$, por el contrario, vemos la prosopopeya desde un punto de vista discursivo y ético podemos ir más allá de las especulaciones de Paul de Man.

Considerada no como una mera operación lingüística limitadora, sino como una función de discursos que producen un sentido de la realidad, la prosopopeya ya no puede verse como una operación despojadora de una realidad que supuestamente preexiste a la autobiografía sino como una operación creadora de esa realidad. En este contexto, como señalan Laclau y Mouffe, resulta indispensable recordar «el carácter material de toda estructura discursiva,» lo cual hace posible una superación de la dicotomía entre una presunta realidad objetiva que existiría fuera del discurso y el discurso considerado como «la pura expresión del pensamiento» (Laclau y Mouffe 1993, pág. 108). No hay una realidad (objetiva) fuera del discurso; por el contrario, las prácticas discursivas construyen la realidad. En 
otras palabras, en el caso de la autobiografía puede afirmarse que hay vida fuera del discurso, pero esa vida no tiene sentido fuera de las construcciones autobiográficas: la vida no tiene sentido; los textos autobiográficos, sí lo tienen o al menos aspiran a crearlo. Las autobiografías le dan a la vida una apariencia de sentido, construyen el significado a través de la mediación indispensable de discursos que, por una parte, tienen que ser colectivos y, por la otra, nunca pueden saturar o suturar completamente la realidad, lo que los convierte siempre en inadecuados y refutables. Como actividad discursiva, la autobiografía se mueve por lo tanto en un dominio temático que debe ser no-original si quiere ser significativo; pero si toda vida no es nunca original, siempre es singular, irrepetible, única y, por consiguiente, irrepresentable en última instancia. Debemos pasar así de una consideración cognoscitiva de la autobiografía (la cual nos ha llevado a la naturaleza discursiva de la prosopopeya) para considerar ahora la autobiografia como decir, como acto ético, como respuesta y legado al otro.

Mientras que los discursos que componen una autobiografía pueden ser cuestionados y, con suficiente perspectiva temporal, muestran su naturaleza convencional, la estructura ética de comunicación al otro que caracteriza a la autobiografía como decir garantiza que la autobiografía nunca es una ficción, sin que importe lo ingenuas o equivocadas que sean las asunciones de su autor acerca de la naturaleza del lenguaje y de la eficacia restauradora de la autobiografía. En consecuencia, debemos ver la autobiografía como un acto performativo y no como una operación cognoscitiva. En resumen, por medio de un desplazamiento del estudio de la autobiografía del terreno de lo epistemológico al de lo discursivo y de lo ético podemos evitar los problemas a los que se enfrentan aquellos que, ya desde Gusdorf (1991), postulan que el momento de mayor verdad de la autobiografía reside en el momento de la escritura (y siguen así considerando la autobiografía fundamentalmente como un acto cognoscitivo); y, al mismo tiempo, con ese desplazamiento del estudio de la autobiografía a lo discursivo y a lo ético, podemos soslayar también las dificultades planteadas por de Man (1991) a toda consideración epistemológica de la autobiografía, yendo más allá de este tipo de concepción, lo cual se logra pasando al terreno de la autobiografía como ética. De Man estaría en lo cierto si la autobiografía fuera simplemente un acto restaurador del pasado; pero la concepción del sujeto que se ha esbozado aquí nos deja ver la necesidad de ir más allá del conocimiento, hacia el terreno de la ética que lo antecede y lo subyace.

Si una correcta comprensión del papel constituyente de la prosopopeya, tal como muestra de Man (1991), priva a la autobiografía de sus ilusiones epistemológicas, una reconsideración de esa figura nos muestra nuevos caminos para un 
entendimiento ético de la autoescritura. Dos asuntos en particular requieren atención: primero, un retorno a la definición clásica de la prosopopeya, la cual acentúa aspectos que aparecen como secundarios en las caracterizaciones de esa figura prevalentes en tiempos modernos; y segundo, un examen de los estrechos lazos de esa figura con la del apóstrofe. Quintiliano llama a la prosopopeya «fictio personae» y su definición consiste en dos partes claramente diferenciadas, de las cuales la primera sirve, en palabras de Quintiliano, para «mostrar los pensamientos internos de nuestros adversarios como si estuvieran hablándose a sí mismos...; o... podemos presentar conversaciones entre nosotros y otras personas, o entre otras gentes, y podemos poner palabras de consejo, reproche, queja, alabanza o compasión en las bocas de las personas apropiadas» (Quintiliano 1980-1989, \# 9.230-31). Estos rasgos de la prosopopeya, que en la retórica clásica son reunidos bajo la rúbrica de «sermocinatio» o «etopeia» apenas reciben atención en definiciones modernas de la prosopopeya como las de Hugh Blair o Fontanier (1977), y están igualmente ausentes de formulaciones contemporáneas como las de Paul de Man (1991) o de Riffaterre (1985). Quintiliano continúa su descripción de la prosopopeya con una caracterización secundaria, según la cual la prosopopeia da rostro o voz a entes «irracionales» (muertos, seres fantásticos, gente imaginaria o ausente, colectividades como la patria), o incluso entidades abstractas (como la justicia) (\# 9.2.58); por el contrario, la etopeya se reserva para dar habla a gente real o viva, y señala que otros prefieren llamarla «mimesis» (\# 9.2.58). En conclusión, al resaltar, o al criticar, los poderes restauradores de la autobiografía (acentúando por consiguiente los aspectos cognoscitivos de la prosopopeya a expensas de su dimensión ético-política) los intérpretes contemporáneos dejan de lado la dimensión dialógica a la que Quintiliano da primacía en su definición. Sin embargo, en su sentido primordial la prosopopeya no intenta llevar a cabo la representación fantasmática de un ente ausente sino que da forma a la dimensión relacional del yo, a su estructura conflictiva de comunicación. Esta capacidad de representar la configuración adversarial de la conciencia (ese esencial dirigirse al otro) es lo que hace de la prosopopeya una figura tan apta para la autobiografía, siempre y cuando entendamos ese tipo de escritura como una empresa discursiva y dirigida al otro, y no como una imposible restauración epistemológica que como tal será inevitablemente «desfiguradora». Como representación de las voces de la alteridad, la prosopopeya es la figura y herramienta perfecta de la escritura autobiográfica.

En el contexto judicial (y el acto autobiográfico muy a menudo imita esa escena) la prosopopeya aparece a menudo acompañada de otra figura retórica que juega un papel prominente en el funcionamiento ético-discursivo de la autobiografía. Me refiero al apóstrofe, del cual se ocupa Quintiliano inmediatamente des- 
pués de tratar de la prosopopeya, y al que caracteriza como el dejar de dirigirse el hablante al juez para dirigirse en cambio a otro destinatario. Estructuralmente, por lo tanto, el apóstrofe tiene una estructura tripolar, y esa misma estructura, como veremos, caracteriza al acto autobiográfico como decir. En la escritura autobiográfica, el apóstrofe pone de relieve el funcionamiento de la prosopopeya al dejar en evidencia claramente la naturaleza dialógica de ésta última, su constitución como respuesta y responsabilidad hacia el otro. Este tener que responder de sí en que consiste la autobiografía hace que este tipo de escritura exceda la mera representación cognoscitiva y muestre claramente su composición ética. No los detalles de una vida, sino el que el autobiógrafo los diga, constituye el aspecto fundamental de la autobiografía, con tal que entendamos que tal «decir» es tanto una respuesta como un legado al otro. De esta manera, el apóstrofe complementa de manera indispensable a la prosopopeya al dejar ver que, si como «dicho» la autobiografía se ocupa del pasado, como «decir» no sólo se centra en el presente sino que también mira hacia el futuro y, como tal, revela esa «estructura testamentaria» que, en The Ear of the Other, Derrida postula para todo texto en general y para la autobiografía en particular.

La autobiografía muestra su naturaleza de orientación hacia el otro y hacia el futuro por medio de la presencia de destinatarios textuales, los cuales siempre están necesariamente presentes en la autobiografía (más que en ningún otro género) a veces de manera implícita, pero muy a menudo de modo explícito. $Y$ es al poner de relieve estos destinatarios cuando el apóstrofe revela su papel definitorio en la autobiografía. Ya San Agustín dedica considerable espacio en sus Confesiones a la respectiva importancia de los dos destinatarios esenciales del relato de su vida, Dios y los lectores, así como a la relación entre ellos. A la pregunta implícita de por qué se confiesa a Dios por escrito, cuando Él lo sabe todo, San Agustín se pregunta: «Por qué, entonces, me importa que los hombres oigan lo que tengo que confesar...?» (San Agustín 1961, \# X.3). No resulta sorprendente tampoco que los destinatarios jueguen un papel estructural indispensable en las Confesiones de Rousseau. A pesar de sus protestas, al contrario, Rousseau concibe la historia de su vida como una apología, dado que, como señala Lejeune, fue escrita primordialmente como una respuesta a sus enemigos (1994, pág. 48). Obsesionado con tramas, traiciones y engaños ( «el techo bajo el que vivo tiene ojos, las paredes que me rodean tienen orejas, rodeado de espías y vigilantes malévolos, anxioso y preocupado me apresuro a poner sobre el papel unas palabras interrumpidas que casi apenas puedo releer») (Rousseau 1959a, pág. 279). Rousseau no sólo escribe su vida como respuesta a los otros, sino que también traspasa la responsabilidad de su lectura al lector. Rousseau reconoce que no intenta contar la verdad de su vida sino que sólo trata de presentar los hechos, sin 
preocuparse por omisiones o errores, dado que su objetivo no es ofrecer la historia externa de su vida sino presentar la historia de su alma (Rousseau 1959a, pág. 278), de modo que resulte transparente al lector, quien es en última instancia responsable de la interpretación de su autobiografía: «De él depende el reunir esos elementos y determinar al ser compuesto con ellos; el resultado debe ser tarea suya, y si se equivoca, el error será sólo suyo» (Rousseau 1959a, pág. 175).

El fracaso de las Confesiones como texto apologético en una serie de lecturas privadas que ofreció Rousseau, exacerbó sus temores y esto, a su vez, lo llevó a escribir un nuevo texto autobiográfico, el cual, en su opinión, mostraría una objetividad perfecta. Con este fin en mente, estructuró Rousseau juge de Jean-Jaques (Rousseau escribe su nombre de manera diferente a la contemporánea) como un diálogo tripolar entre un francés (emblema de sus enemigos), Rousseau (un doble supuestamente imparcial) y Jean-Jaques (quien representa el Rousseau íntimo, auténtico). Motivado por «la increíble ceguera de los lectores» a la hora de discernir el propósito de sus Confesiones, Rousseau siente la necesidad de «decir, cómo, si yo fuera otro, vería a un hombre como yo» (Rousseau 1959b, pág. 665). A la vista de la injusticia del otro, de su ceguera y su juicio delirante que «desfigura y difama a placer» (Rousseau 1959b, pág. 665), Rousseau se siente obligado a tomar el lugar del otro, a intentar convertirse en otro con el fin de enunciar la verdad acerca de sí mismo, y esa estratagema narrativa de Rousseau resulta en la dramatización del espacio judicial del apóstrofe. Aunque en las Confesiones Rousseau invoca la supuesta imparcialidad de sus lectores como jueces últimos de su narración de la verdad, sabemos que en realidad él busca convencer a sus enemigos: tenemos ya aquí la tríada de la configuración judicial del apóstrofe, puesto que Rousseau se dirige directamente al lector/juez pero en realidad, indirectamente, habla para el juez que en verdad le importa, sus enemigos: el camino a la verdad autobiográfica es siempre indirecto. Cuando la recepción que reciben las lecturas privadas de las Confesiones le lleva a darse cuenta de que los lectores no son los jueces honestos que él creyó, Rousseau crea una nueva respuesta autobiográfica, Rousseau juge de Jean-Jaques, centrada alrededor de un nuevo triángulo (Jean-Jaques, Rousseau, el Francés). Esta obra «dramatiza» explícitamente los papeles apostróficos que aparecen en las Confesiones de manera más implícita, pues el destinatario directo de esta última obra (el supuesto lector/juez imparcial) se convierte ahora en Rousseau, mientras que la figura de sus enemigos, implícita en las Confesiones, está ahora representada abiertamente por el Francés.

Considerados generalmente como la manifestación paradigmática de la autobiografía moderna, los textos de Rousseau presentan de manera ostensible la 
triangulación que propongo como estructura fundamental de la autoescritura. El hecho de que Rousseau utilice la tríada apostrófica con el propósito confesado de alcanzar una verdad interna y última no debería impedirnos ver cuáles son los parámetros fundamentales envueltos en su estrategia. Rousseau es consciente, aunque tal vez sólo indirectamente, de que su búsqueda obstinada de la verdad nunca llegará a su final y, en consecuencia, recurre una vez más a la seguridad última del juicio honesto de Dios (Rousseau 1959b, pág. 666). Rousseau tematiza su alegato en términos de verdad y engaño, pero en ese proceso revela las dimensiones éticas, inequívocas e inescapables, de la escritura autobiográfica, dado que toda autorreflexión supone una duplicación del yo que pasa inevitablemente por el otro, con lo que la búsqueda de la verdad interna se convierte en un ejercicio infinito que no va directamente del yo al yo, sino que tiene que pasar siempre por el otro: el camino a la propia conciencia pasa siempre a través del otro. Tanto para San Agustín como para Rousseau, Dios actúa como un «suplemento» que pararía la infinita maquinaria ética de la autobiografía. En última instancia, sin embargo, y a pesar del hecho de que el recurso a un Dios justo y omnisciente haría innecesario el relato autobiográfico, tanto San Agustín como Rousseau se sienten obligados a escribir sus vidas, lo cual indica que el verdadero asunto y vocación de la autobiografía es el decir ético de la verdad, y no la manifestación en lo dicho de la verdad en sí.

Tanto la tríada apostrófica como la preeminencia de la carga ética de la autobiografia quedan en evidencia en Circumfession, el texto autobiográfico de Derrida. Jugando con los significados de circuncisión y confesión, el título de Derrida encierra también la circunvalación a través de los otros presupuesta en el apóstrofe autobiográfico. Ese rodeo apostrófico se muestra de manera patente en la cita que ofrezco a continuación, en la cual Derrida dibuja un triángulo entre su yo narrativo, el lector y su madre moribunda y parcialmente amnésica: «la admisión que le debo al lector, en verdad que le debo a mi madre misma, pues el lector ya habrá comprendido que yo estoy escribiendo para mi madre, tal vez incluso para una mujer muerta,» aunque, Derrida aclara, «si estuviera escribiendo para mi madre sería para una madre viva que no reconoce a su hijo y estoy dando explicaciones aquí para alguien que ya no me reconoce.» $Y$ la fundamentación ética de la autoescritura como responsabilidad, que Derrida parece reducir a la búsqueda del perdón, es también traída a un primer plano: «la verdad esencial de la confesión ... no tiene nada que ver con la verdad, sino que consiste ... en el perdón pedido, o mejor aún, en una petición ... ante el uno y el otro quienes son los únicos que tienen el derecho en esta ocasión a perdonar, al perdón, a nada» (Derrida 1993, págs. 25, 48-49). 
También Philip Roth en The Facts, uno de los relatos autobiográficos más lucidos y fascinantes de nuestra época, pone de relieve la mayor parte de las características de la autobiografía que he presentado. Aunque Roth escribe que «la persona para quien he intentado hacerme visible aquí ha sido, primariamente, yo mismo» (Roth 1988, pág. 4), su relato comienza con una carta que Roth dirige a Zucherman, uno de sus personajes de ficción, mostrando así ya desde el comienzo que la autobiografía es un acto dialógico que se dirige siempre al otro y que requiere una respuesta. Ésta toma aquí la forma de una carta, en la que Zuckerman evalúa The Facts como relato autobiográfico, carta que al mismo tiempo que cierra la obra de Roth la deja abierta a nuevas respuestas y requerimientos. Al mismo tiempo, Roth concede importancia decisiva a otra manifestación ética de la autobiografía, «el cuidado de uno mismo» postulado por Foucault (que no he podido discutir aquí por falta de espacio), cuando explica que su libro se originó en la necesidad de «recuperar algo que había perdido» durante un período de depresión profunda, lo que le lleva a escribir lo siguiente: «Aquí, como si se tratara de regresar a mi vida anterior, de recobrar mi vitalidad, de transformarme en mi mismo, empecé a plasmar mi experiencia sin transformaciones» (Roth 1988, pág. 5). Aunque a estas alturas podemos mostrarnos escépticos ante esas referencias rothianas al autoconocimiento, su intento de auto-redescubrimiento es innegablemente verdadero como acto ético.

\section{LA VERDAD: FICCIONES Y PROMESAS}

Para resumir, lo esencial de la autobiografía son sus dimensiones discursiva, ética y retórica. Un análisis de la autobiografía deberá comenzar por consiguiente con un desvelamiento de los discursos (múltiples, heterogéneos y a menudo en conflicto entre sí) que componen la trama de las narraciones autobiográficas. Y aunque esos discursos son necesariamente contingentes, cambiantes con la época y el contexto de cada autor, no debemos caer en la trampa de verlos como ficciones o falsedades. A la hora de teorizar la constitución del sujeto, buena parte de los pensadores contemporáneos más importantes (Foucault, Deleuze y Guattari, Lacan, Levinas) postulan una fase inicial de (auto)afección que funciona como un suelo o matriz de un segundo estadio (sociopolítico, colectivo, simbólico) de la composición del sujeto. Los discursos que estructuran al sujeto en esta segunda fase no podrían operar si no estuviese establecida previamente una disposición afectiva, una receptividad a dejarse afectar, y es en este punto en el que me parece que la formulación de Levinas es mucho más convincente que la de los otros pensadores que acabo de mencionar. Mientras que ni Foucault ni Deleuze y Guattari especifican muy claramente la articulación de esos dos esta- 
dios, y mientras que Lacan, por su parte, deja de lado la dimensión afectiva para favorecer en su lugar una identificación especular, Levinas concede prominencia a la huella afectiva del otro en la constitución del sujeto como deuda y responsabilidad. Y aunque, en contra de lo que especula Lacan, el sujeto no se inicia como una ficción que haría de la vida una fantasmática, la alteridad originaria del sujeto postulada por Levinas hace del sujeto una incompletitud que necesita a ese otro ante el que tiene que responder. De esta manera, esa primera fase afectiva a la que me acabo de referir constituye, por una parte, el fundamento de la obligación que tiene el yo de oír y seguir la voz ordenadora del orden colectivo, mientras que, por la otra, ese dejarse afectar llevará al sujeto a aferrarse apasionadamente a las órdenes de la colectividad, a hablar por ellas y con ellas como si se tratara de su propia sustancia, mientras que, simultáneamente, la naturaleza misma del poder, como aduce Foucault, otorga al yo la libertad de desoír, resistir o desobedecer esas imposiciones del orden sociopolítico. Otra ventaja de la formulación del sujeto postulada por Levinas es su insistencia, compartida por Derrida, en que la alteridad constituyente del sujeto depuesto lo convierte en una singularidad, ya que nadie puede tomar su lugar y responder por él. De esta manera, uno de los mayores dilemas de la teoría actual (el sujeto como construcción frente al sujeto como sustancia) se muestra como una opción equivocada, puesto que el sujeto puede ser (es) simultáneamente una construcción y una singularidad, algo único. Sin embargo, esta doble constitución del sujeto impide que pueda ser visto como una ficción, e impide también argumentar que, dado que es una construcción, la verdadera identidad del sujeto reside en otra parte, o que el sujeto tiene libertad para cambiar posiciones a voluntad. La creencia actual, predominante en cierta tradición teórica anglosajona, en una razón o una voluntad sin límites aparentes debe ser atemperada con la afirmación de Deleuze y Guattari de que tanto la razón como la voluntad no son más que fuerzas que funcionan en relación con otras muchas.

El sujeto autobiográfico, por lo tanto, sólo se puede manifestar por medio de discursos comunitarios que son históricos, y así datados y fungibles, pero también imposiciones inevitables, y por esa razón el sujeto cree necesariamente que esos discursos ofrecen una representación fiel del pasado. Y me gustaría insistir en que la crítica autobiográfica sólo debería examinar esa creencia en la verdad (y no la verdad como correspondencia con la realidad o la verdad como algo escondido a recuperar) y el deseo de autoconocimiento que acompaña a esa creencia. En este sentido hay tres aspectos, relacionados entre sí, que contravienen las ilusiones cognoscitivas del sujeto: la incapacidad de cualquier conjunto de discursos de contener o explicar la vida narrada; las irrupciones e interrupciones de lo que yo llamaría de manera general caos o trauma; y la subversión de los dominios epis- 
temológico y político ocasionada por las manifestaciones de lo ético como responsabilidad ante y hacia el otro. La imposibilidad de la autobiografía de alcanzar una saturación discursiva del pasado puede ser discernida en los varios modos en que el tejido narrativo es perturbado: fragmentaciones, dudas narrativas, explicaciones y perspectivas múltiples y potencialmente en conflicto entre sí, fisuras en el diseño teleológico, rupturas que impiden que el relato alcance un cierre coherente, etc. Esas perturbaciones se dan en toda autobiografía, pero aparecen especialmente cuando el autobiógrafo trata de representar la irrupción del azar, crisis, traumas, epifanías sobre su identidad, una inmersión en las tinieblas, una confrontación inesperada con experiencias límite como la muerte u otra forma de destrucción, dudas acerca de su identidad y, tal vez, simplemente cuando trata de explicar su derecho a ser: en otras palabras, me estoy refiriendo a todos esos fenómenos cuya representación hace a unas autobiografías más interesantes que otras. En todo caso, la presencia en toda autobiografía de discursos heterogéneos y en conflicto entre sí pone de relieve la inestabilidad intrínseca a la autobiografía como género, inestabilidad que ya se percibe en sus manifestaciones clásicas, y que es abordada explícitamente por muchos autobiógrafos modernos en forma de reflexiones metaficcionales, las cuales son tematizadas a menudo por medio de tramas aleatorias, como es el caso de Roland Barthes por Roland Barthes (1977). En sus manifestaciones límite, esta ironía autorial puede convertirse en parodia o pastiche.

En resumidas cuentas, el referente autobiográfico es siempre recalcitrante, se resiste siempre a ser saturado o suturado por ninguna combinación de discursos explicativos, pero esta resistencia de ninguna manera supone un peligro para el género autobiográfico pues lo que nos revela es que la autobiografía no es una restauración del pasado sino un acto singular de autocreación como respuesta, responsabilidad y promesa (de verdad). Como tal, este acto es siempre dialógico, está dirigido al otro, y por lo tanto es siempre intrínsecamente contestable e incompleto. Podría decirse, entonces, que la retórica performativa presente en la autobiografía no desestabiliza (como aduce Paul de Man, 1991) sus pretensiones epistemológicas, sino que las supera, puesto que si la autobiografía fracasa necesariamente como empresa cognoscitiva, triunfa siempre como acto performativo, ético, dirigido al otro: aunque la autobiografía nunca puede representar la verdad, siempre presentará el deseo del sujeto de autoconocerse y su promesa de verdad-simplemente promesa, no realidad. 


\section{BIBLIOGRAFÍA}

BARTHES, Roland. 1977. Roland Barthes by Roland Barthes, New York, Wang and Hill.

DELEUZE, Guilles. 1995. Negotiations. 1972-1990, New York, Columbia University Press.

DELEUZE, Guilles y GUATTARI, Félix. 1994. A Thousand Plateaus. Capitalism and Schizophrenia, Minneapolis, University of Minnesota Press.

DE MAN, Paul. 1991. «La autobiografía como desfiguración», Suplementos Anthropos XXIX, número La autobiografía y sus problemas teóricos, págs. 113-118.

DERRIDA, Jacques. 1978. «Violence and Metaphysics», en Writing and Difference, Chicago, Chicago University Press, págs. 79-153.

- 1988. The Ear of the Other, ed. Christie MCDONALD, Lincoln, University of Nebraska Press.

- 1993. «Circumfession», en Geoffrey BENNINGTON y Jacques DERRIDA, Jacques Derrida, Chicago, Chicago University Press.

FONTANIER. [1830] 1977. Les figures du discours, Paris, Flammarion.

FRIEDMAN, Susan Stanford. 1994. «El yo autobiográfico de la mujer: teoría y práctica», en Ángel G. LOUREIRO (coord.), El gran desafio: feminismos, autobiografía y postmodernidad, Madrid, Megazul-Endymión, págs. 151-186.

GUSDORF, Georges. 1991. "Condiciones y límites de la autobiografía», Suplementos Anthropos XXIX, número La autobiografía y sus problemas teóricos, págs. 9-18.

KEARNEY, Richard. 1984. «Dialogue with Emmanuel Levinas», en Dialogues with Contemporary Philosophers. The Phenomenological Heritage, Manchester, Manchester University Press, págs. 105-126.

LACLAU, Ernesto y MOUFFE, Chantal. 1993. Hegemony and Socialist Strategy. Towards a Radical Democratic Politics, Londres, Verso.

LEJEUNE, Philippe. 1994. El pacto autobiográfico y otros estudios, coord. Angel G. LOUREIRO, Madrid, Megazul-Endymión. 
LEVINAS, Emmanuel. 1985. Ethics and Infinity. Conversations with Philippe Nemo, Pittsburgh, Duquene University Press.

- 1989. «God and Philosophy,» en Seán HAND (ed.), The Levinas Reader, Oxford, Basil Blackwell, págs. 166-189.

- 1990. Autrement q'être ou au-dela de l'essence, Paris, Le Livre de Poche.

- 1993. Outside the Subject, London, The Athlone Press.

QUINTILIANO. 1980-1989. Institutio Oratoria, 4 vol., Cambridge, Harvard University Press.

RIFFATERRE, Michael. «Prosopopeia», en Peter Brooks et al (eds.), The Lessons of Paul de Man, Yale French Studies LIX, 1985, págs. 107-123.

ROTH, Philip. 1988. The Facts. New York, Farrar, Straus \& Giroux.

ROUSSEAU, Jean-Jacques. 1959a. Les Confessions, vol. 1 de Oeuvres complètes, ed. Bernard GAGNEBIN y Marcel RAYMOND, Paris, Gallimard, págs. $1-656$.

- 1959b. Rousseau juge de Jean-Jaques, vol. 1 de Oeuvres complètes, eds. Bernard GAGNEBIN y Marcel RAYMOND, Paris, Gallimard, págs. 657-992.

SAN AGUSTÍN. 1961. Confessions, Harmondsworth, Penguin.

SOMMER, Doris. 1994. «"Más que una mera historia personal": los testimonios de mujeres y el sujeto plural», en Angel G. LOUREIRO (coord.), El gran desafio: feminismos, autobiografia y postmodernidad, Madrid, Megazul-Endymión, págs. 295-329. 